1994: Salager-Meyer, F. "Hedges and textual communicative function in medical English written discourse." English for Specific Purposes. 13(2), 149-171

Françoise Salager-Meyer, Apartado 715. MERIDA. 5101. VENEZUELA. Home phone number: International .+ 58-74-66-02-89. Fax: Intern.+ 58-74-40-27-15 or International +58-74-66-02-89

\title{
Hedges and Textual Communicative Function in Medical English Written Discourse \#*
}

\author{
Françoise Salager-Meyer
}

\begin{abstract}
This paper discusses how the communicative purpose of the different rhetorical sections of research papers (RP) and case reports $(\mathrm{CR})$ in medical English written discourse influences the frequency and category distribution of the modulation devices (hedges) used in each section.

To this end, we analyzed a corpus of 15 articles drawn from five leading medical journals. Hedges were identified by means of a contextual analysis, their frequency was recorded in the different rhetorical sections of the 15 articles, and their percentages (over the total number of running words) were computed. The hedges recorded were then classified according to five pre-established categories, and their percentual distribution per category was evaluated in each rhetorical section. The results were analyzed by means of Chi-square tests.

Our research indicates that the three most frequently used hedging devices in both text-types (shields, approximators and compound hedges) account for over $90 \%$ of the total number of hedges used in our sample. The Discussion (RP)/Comment (CR) sections are the most heavily hedged sections, whereas the Methods (RP) and the Case Report sections (CR) are the least-hedged rhetorical divisions ( $\mathrm{p}=.001$ and .071 respectively). The Introduction section of both RP and CR favors shields (mainly epistemic verbs) as a hedging convention followed by approximators (negative or quasi negative expressions in RP Introductions, and adaptors of frequency in CR Introductions). In the Introduction hedges allow researchers to establish an "early niche" for their research. Scientific writers mostly resort to approximators as a hedging technique in the Methods section $(\mathrm{p}=.0001)$ as well as in the Results sections of RP and in the Case Report sections of CR. Shields (mostly modal verbs) are also used (although to a much lesser extent) in the Result section of $\mathrm{RP}$ to evaluate, interpret and comment on the findings of the research being reported. Both shields and compound-hedges are the most frequently encountered hedging devices in the Discussion/Comments sections of RP and CR. Finally, the distribution of hedges in the Case Report section in CR resembles that observed in the Result section in RP, but it is significantly richer in approximators $(\mathrm{p}=.0001)$ used for describing symptoms and for conveying the idea of range.
\end{abstract}

We conclude that the choice of expressions of tentativeness and flexibility is dictated by the general structure of the discourse, by its communicative purpose, by the level of claim the writers wish to make, and by the authors' pretension to universality and generalization.

Because hedging in scientific discourse is a necessary and vitally important skill, we finally provide some pedagogical implications of our research such as the use of sensitization, translation and rewriting exercises in ESP courses.

\section{INTRODUCTION}

Today's scientists are urged to use a style of writing which projects both personal modesty and honesty. Argumental arrogance and exuberance are not well seen by the scientific community. By 
contrast, humility, coyness and cautiousness are. As Myers puts it (1988), researchers have to present themselves as "the humble servants of the discipline."1 According to Blisset (1972: 141): "If a scientist is articulate, persuasive, if he goes to the heart of the matter, he is open to attack." As a consequence, everything must be toned down; speculation can obviously be made but it must be apologized for. In order to reach this goal, i.e., to tone down their statements, researchers have a variety of linguistic devices available which generally go under the rubric of "hedges." The literature on the subject provides us with two conflicting --although not mutually exclusive-standpoints on the raison d'être of hedges.

The first (and most widely accepted) view associates hedges with unscientific imprecision and defines them as "linguistic cues of bias" (Fand 1989), i.e., understatements used to convey (purposive) vagueness and tentativeness, and to make sentences more acceptable to the hearer/reader, thus increasing their chance of ratification and reducing the risk of negation. This necessity for ratification is caused by the inherent refutability of sentences. Indeed, Lakoff (1972) pointed out that natural language sentences are very often neither true nor false nor nonsensical, but rather true to a certain extent and false to a certain extent, true in certain respects and false in others. He then referred to hedges as "words or phrases whose job is to make things more or less fuzzy." Along the same lines, Myers (1988) argued that claiming precision is not appropriate in all situations and that scientists do not always want to be precise: "Sometimes we want to be vague," assert Kong et al. (1986). This concept of fuzziness and (necessary) imprecision was developed further by other researchers, such as Brown and Levinson (1978) who considered hedges as strategies for minimizing the threat to face that lurks behind every act of communication, Lachowicz (1981), Prince et al. (1982), Rounds (1982), Powell (1985), Pindi et al. (1986), Skelton (1988), Dubois (1987), Vasquez (1987). They all, in one way or another, state that hedges are used to signal distance, to "unobtrusively inject an author's personal view into his communication" (Dubois 1987: 539), to protect one's own reputation as a scientist, to avoid absolute statements which might put the researchers (and the institution they work at) in an embarrassing situation, to express the extent to which the writers commit themselves to the truth value of their statements and to allow the researchers to be more open to other possibilities of interpretation. According to Swales (1990: 175), hedges are rhetorical devices used for "projecting honesty, modesty and proper caution in self-reports and for diplomatically creating space in areas heavily populated by other researchers." Quite originally (although not completely at variance with the previous definitions),

\footnotetext{
1 Myers (1985) provides us with a nicely illustrated case study of two well-established biologists who struggled to get their papers published because their arguments were too arrogantly expressed. As Myers observes, the authors had to rewrite their article four times, "so that the published versions are hardly recognizable as related to the first submission." (1985: 594).
} 
Myers (1988), basing his discussion on Brown and Levinson's work (1978), argues that hedges can be better understood as positive or negative "politeness strategies", i.e., as rational strategies used for dealing with the social interactions involved in publishing an article (e.g., solidarity with readers, unspeakability of direct criticisms, deference towards the scientific community).

The proponents of the other viewpoint consider that the association of hedging with vagueness or fuzziness can obscure some important function of hedging (cf. Salager-Meyer 1993). Instead of interpreting the use of hedgings solely in this way, one could alternatively consider them as ways of being more precise in reporting results. Hedging may present the true state of the writers' understanding, namely, the strongest claim a careful researcher can make. Referring to academic writing, Rounds (1981) argues that hedges are not used simply to cover oneself and to make things fuzzy, but that they can also be used to negotiate the right representation of the state of the knowledge under discussion, i.e., to achieve greater preciseness in scientific claims. Indeed, as Tarantino explains (1991a.), all along scientific writers are aware that the fragment of truth they are exploring is only another step towards the discovery of other truths which will in turn advance knowledge and understanding of nature. In their search for truth (a direction in which all scientists are moving but which is not something one ever finally achieves) and "through the attentive and painstaking organization of their thoughts, scientists ackowledge that their contribution is a mere glimmer of light in the stream of endeavours to investigate and penetrate the wondrous mystery which include man and the universe." (Tarantino 1991b.: 33). We then partly agree with Skelton (1988) that hedges should not always be considered as a problem, as a "cover-up" tactic, but rather as a resource to express scientific uncertainty, skepticism and doubt. After all, scientific rationality is a myth, as Gilbert and Mulkay argue (1984), and science has always been oscillating between the desire to be precise and the impossibility of accurately quantifying the world. (This is why scientists' eagerness to accuracy is very often frustrated).

Some of the previously mentioned studies were concerned with the use of hedges in general language texts (McKinley 1983, Powell 1985, Stubb 1986, Zuck and Zuck 1987, Skelton 1988), others dealt with the phenomenon of hedging in academic writing (Adams Smith 1983, 1984 and Kubui 1988 in medical research papers, Rounds 1981, 1982 in social sciences, Prince et al. 1982 in physician-physician oral discourse, Pindi et al. 1986 in economic forecasting, Dubois 1987 in biomedical slide talks, Myers 1988 in a corpus of molecular genetics), and others discussed the problem from a contrastive rhetorics point of view (Markanen and Schröder 1988 a.b, Clyne 1991). However, we do not know of any study which has focused on the problem of how hedgings are realized in different text-types (or sub-genres) within one and the same genre, i.e., how the communicative purpose or situational context of different text-types --each having its own quite 
separate conventions, processes of reasoning and standards of arguments-- influences the range of modulations used and the variety of its linguistic realizations. In the words of Yearley (1981): "An analysis of the manner in which scientific texts are composed argumentatively will be central to any project concerned with the nature of scientific evaluation."

Last but not least, I believe that in spite of their undeniable contribution to the field, most studies which have been carried out so far on the topic of hedges have not made enough emphasis upon the fact that hedges are first and foremost the product of a mental attitude which looks for prototypical linguistic forms (such as modals, epistemic verbs, approximators, etc. ) for its realization, but these linguistic forms do not always carry a hedging nuance. Such an ambiguity -- one linguistic form may serve many functions and the same function may be expressed using different forms-- leads to the difficulty of identifying which of these linguistic forms are hedges and which are not. Nevertheless, it is my contention that the gap which necessarily exists between the writer's mental processes (i.e., his/her intentions) and the linguistic realizations employed can be solved to a great extent by carrying out a rigorous contextual analysis.

\section{THE STUDY}

The research reported here is part of a wider genre-based contextual analysis on the use of hedging in today's medical English (ME) written discourse, the broad objective of which is to examine how the communicative function (or discursive practice) of the four fundamental ME text-types (viz., editorials [ED], review articles [RV], research papers [RP] and case reports [CR]) influences the frequency and distribution of hedging conventions used in each text-type (or sub-genre) ${ }^{2}$. As was said before, our research differs from most other studies in the sense that it is both a "bottom-up" applied study which examines the phenomenon of hedging in the specific written genre of ME scholarly papers, and a "top-down" study of discourse which aims at developing an understanding of this phenomenon across different text-types by quantitatively and qualitatively relating it to the communicative purpose of each text-type. That hedging is basic to academic discourse (Rounds 1982 ) is the underlying assumption of our research project. ${ }^{3}$

\footnotetext{
2 The importance of genre studies and that of the classification and description of genres and sub-genres for both teachers and learners is now well-documented (e.g., Swales 1981, 1990; Hopkins and Dudley-Evans 1988).

3 In this respect, it is interesting to mention that Prince et al. (1982) found that the most salient feature of physicianphysician oral discourse is the number and frequency of hedges: more than 1 every 15 seconds.
} 
In a previous article (Salager-Meyer 1991), it was found that the four above mentioned text-types could be reduced to two on the basis of the frequency and category distribution of hedging conventions used in each text-type: ED/RV on the one hand (heavily hedged argumentative, persuasive and evaluative writing), and RP/CR on the other (more informative and descriptive discourse, less heavily hedged than the previous two sub-genres) ${ }^{4}$. However, in that previous paper, the frequency and distribution of hedging in RP and CR was "globally" recorded, i.e., hedges were recorded regardless of the rhetorical sections in which they occurred.

Because research papers have become "a standard product of the knowledge manufacturing industries" (Knorr-Cetina 1981), and because of their "qualitative and quantitative pre-eminence" (Swales 1990: 93), we decided to carry out a follow-up study to determine how medical writers modulate (or mitigate) their discourse in the different rhetorical sections of RP and CR. It is indeed well-established (e.g., Swales 1990) that research articles cannot be considered as homogeneous discourse: they are divided into 4 or 5 rhetorical sections and there are discernible differences in communicative function from one section to another. In 1958, Toulmin defined the five interrelated constituents of a scientific presentation as follows: the grounds (established information on the subject), the warrant (qualitative and quantitative facts supporting the new hypothesis), the modality (value indicating the degree of certainty regarding the event reported), the claim (the core of the discussion, the conclusion that the report proposes), and the rebuttal (elements of doubt concerning the claim made). It can readily be seen that Toulim's five constituents closely correspond to what is today commonly referred to as the "IMRAD structure" of RP, i. e., this "intellectual straightjacket" (Lock 1988) composed of the Introduction, Methods, Results And Discussion. In CR, this structural pattern is reduced to three constituents, each one having a distinct communicative purpose as well: a short Introduction, a detailed Case Report, and a brief Comment (sometimes called Discussion) section.

\section{PURPOSE}

The objectives of the present paper are threefold:

a. To determine whether the frequency and types of hedging techniques used in the different rhetorical sections of RP and CR vary from one section of the article to the other.

b. Since one way in which choice of tentativeness, flexibility and/or politeness is guided is by the writer's perception of the general purpose of the text being created, we will secondly analyze how

\footnotetext{
4 For a thorough communicative analysis of the fundamental ME text-types considered in our research project, see
} Salager-Meyer 1991. 
the communicative purpose (or discursive practice) of each rhetorical section influences the use of hedging conventions.

c. To elaborate a listing of the various hedging devices typical of today's ME written prose which could readily be used in EMP courses for pedagogical purposes. Indeed, as Rounds (1981), Bloor (1984) and Skelton (1988) agree, since hedging is a common technique of communicating information in scientific discourse, it should be explicitly studied and taught to the students in order to assist them in their studies and professional careers.

Before going any further, it should be kept in mind that the definition of hedges we adopted in the present research goes beyond their mere association with speculation. Indeed, it embraces a threedimensional concept: 1 . that of purposive fuzziness and vagueness (threat-minimizing strategy); 2. that which reflects the authors' modesty for their achievements and avoidance of personal involvement; 3 ) that related to the impossibility or unwillingness of reaching absolute accuracy and of quantifying all the phenomena under observation.

\section{METHODOLOGY}

We analyzed a corpus of 15 "high-brow level" articles (see Huddleston 1971) distributed as follows: 10 CR (making up a total of 13,958 running words) and 5 RP (making up a total of 11,871 running words). The articles, all published between 1980 and 1990, were drawn from leading medical journals such as The British Medical Journal, Annals of Internal Medicine, The Lancet, Archives of Internal Medicine and The New England Journal of Medicine. These journals were chosen because they embody some of the best in medical journalism.

The number of hedging devices was recorded in each rhetorical section in each article separately, and the percentage of hedges (with respect to the total number of running words making up each rhetorical section in each article) was computed. The results were analyzed by means of Chi-square tests. The alpha value was set up at .05 .

For the reasons stated in the Introduction and in order to identify hedges as accurately and precisely as possible, we carried out a rigorous contextual analysis (both from a linguistic and medical standpoint) of the linguistic expressions commonly considered as hedges. This is why the taxonomy we adopted in this research (see herebelow) contemplates both formal and functional criteria. Obviously, such a procedure does not guarantee a $100 \%$ reliability rate in the adscription of a given linguistic form to a hedge, but we believe that it is much more reliable than a "blind" (i.e., non- 
functional, purely formal) identification which would undoubtedly lead to the distorsion of the data both in their quantity and their distribution.

The taxonomy of hedges we adopted in this paper is then the following:

1. Shields: all modal verbs expressing possibility ${ }^{5}$; semi-auxiliaries like "to appear," " to seem" (also called "plausibility shields" in Prince et al. [1982]); probability adverbs like "probably," "likely" and their derivative adjectives; epistemic verbs (that is, verbs which relate to the probability of a proposition or a hypothesis being true) such as "to suggest," "to speculate ".

2. Approximators: stereotyped "adaptors" as well as "rounders" (see Prince et al. 1982) of quantity, degree, frequency and time (e.g.,"approximately," "roughly," "somewhat," "quite," "often, "occasionally" ) which express heed and coyness. According to our working definition of hedges (see page 6 above), even though not all approximators serve to make things vague -- some are indeed used when exact figures are irrelevant or unavailable or when the state of knowledge does not allow the scientists to be more precise-- they were all recorded as "hedges". 6 Approximators is the hedging category which most closely reflect what we could call the "institutionalized " language of science.

3. Expressions such as "I believe, " " to our knowledge, " " it is our view that ..." which express the authors' personal doubt and direct involvement;

4. Emotionally-charged intensifiers (comment words used to project the authors'reactions) such as "extremely difficult/interesting, "dishearteningly weak," " of particular importance", "particularly encouraging, " "unexpectedly," "surprisingly."

5. Finally, we decided to add a fifth category labelled "compound hedges" which comprised "strings of hedges" ( i.e., the juxtaposition of several hedges). Such compound hedges can be double hedges (It may suggest that ...; "it could be suggested that "...), treble hedges (It would seem likely that ..., it seems reasonable to assume ), quadruple hedges (It would seem somewhat unlikely that ...), etc.

The hedges recorded in our sample were thus classified according to the five above mentioned categories. In order to appreciate how hedging conventions were distributed in the two text-types under study, the number of hedges per category was computed as a percentage of the total number of hedges recorded in each text-type (the $5 \mathrm{RP}$ and the $15 \mathrm{CR}$ altogether). The same procedure was adopted for the rhetorical sections of RP and CR, i.e., in each rhetorical section the number of

\footnotetext{
5 Modals expressing capability were not recorded as hedges, e.g, "No conclusion can be drawn," "We could not detect any clinical parameter," "We may now turn to review the data so far obtained."

6 Obviously, such expressions as "more than half (58\%)" were not recorded as hedges because in such cases the parenthesis provides the readers with the exact figure.
} 
hedges per category was computed as a percentage of the total number of hedges recorded in each section in order to appreciate how hedging conventions are distributed among the different sections of RP and CR. For the analysis of the data we sought the assistance of a specialist informant, expert in medical research and fluent reader of English, who helped us to confirm and expand the hypotheses generated by the written data analysis.

Finally, we want to mention that the linguistic examples given in this paper are to be considered as typical exponents of a particular rhetorical section (i.e., they belong to the most frequently used categories in a given section and/or text-type). They are all presented in an abbreviated form and in all the cases they have been taken from the articles making up our corpus.

\section{RESULTS AND DISCUSSION}

We will present and discuss the results of the present research as follows ${ }^{7}$ :

a. those related to the overall percentage of hedges in the different rhetorical sections of RP and CR (with respect to the total number of running words in each section);

b. those concerned with the categorical distribution of hedging conventions in the two text-types under study (with respect to the total number of hedges recorded in each text-type) ;

c. those obtained for the categorical distribution of hedges in the different rhetorical sections of RP and CR (with respect to the total number of hedges recorded in each section).

\section{A. Overall percentage of hedging devices in the different rhetorical sections of Research} Papers and Case Reports (with respect to the total number of running words in each division).

As Fig. 1 indicates, the Discussion sections in RP -- as well as their equivalent Comment sections in CR-- are the most heavily-hedged divisions of these two text-types (13\% and $10.7 \%$ respectively of the total number of words making up these sections are hedges). By contrast, the Methods sections in RP and their (situationally) corresponding Case Report sections in CR exhibit the lowest percentage of hedges $(0.8 \%$ and $3.6 \%$ respectively). The results of the statistical tests performed show that the difference between the percentage of hedges recorded in the Discussion sections of $\mathrm{RP}$ and that observed in the Methods sections of RP is statistically significant $(\mathrm{p}=.001)$. What is more, the percentage of hedges recorded in the Discussion sections of RP by far outnumbers that observed in any other section of RP. The results of the tests performed also show that the difference

\footnotetext{
7 The overall percentage of hedges in RP and CR (regardless of their frequency of occurrence per rhetorical section) is
} reported in our first article on the use of hedges in medical prose (Salager-Meyer 1991). 
Salager-Meyer 9

between the frequency of hedges recorded in the Case Report sections of CR and that observed in the Comment 


\section{Figure 1}

Percentage of Hedges per Rhetorical Section in Research Papers (RP) and Case Reports (CR)

(with respect to the total number of running words in each section)

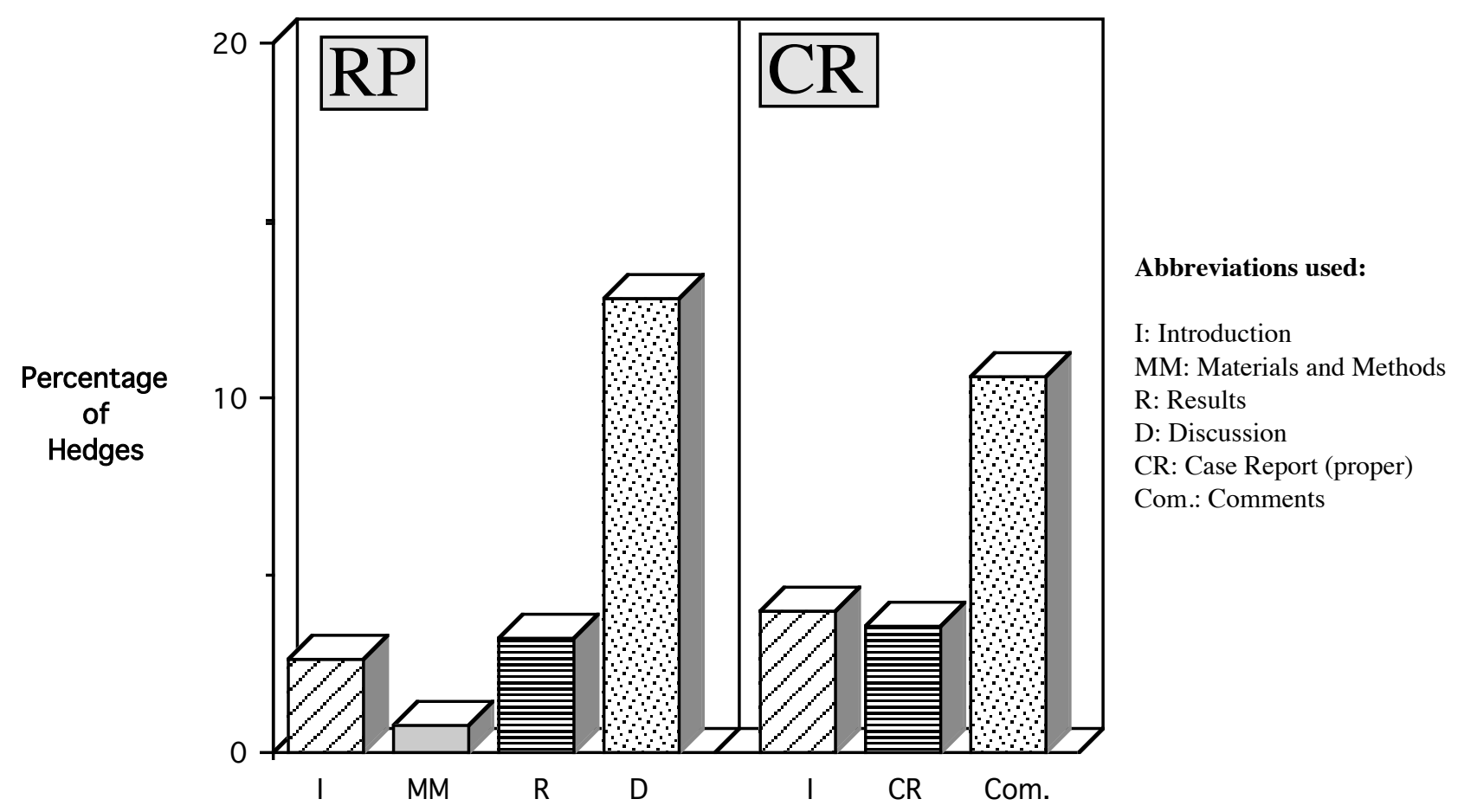

Rhetorical Sections

Statistically significant differences $(p>.05)$

$\mathrm{D}(\mathrm{RP})$ compared with I, MM and R(RP)

Com.(CR) compared with $\mathrm{CR}(\mathrm{CR})$ 
sections of $C R$ almost reaches statistical significance $(p=.0713)$. This confirms other researchers' findings (Swales 1981, 1987, 1990; Yearley 1981) that the Discussion/Comments section of scholarly papers are marked by a heavy use of hedging and modality. The "level of claim the writers wish to make" (Myers 1985) in the different rhetorical sections of a scholarly paper accounts for the difference observed in the percentage of hedging devices used in them. This level of claim --which is in close relation to the writers' pretension to universality or generalizability (see Salager-Meyer 1993)-- is in turn related to the particular communicative purpose of each rhetorical division. (This point will be dealt with in greater detail in section C. below). In this respect, it is interesting to note that the overall percentage of hedges recorded in the Discussion sections of RP (13\%) is greater (although not significantly so) than that observed in the Comment sections of CR (10.7\%). This is very likely due to the fact that CRs (as their name indicates) present a single, rare and unusual entity. This means that their authors cannot pretend to universalize their findings as much as RP writers (who present a "cohort" of cases) do, and, as a consequence, they do not need to tone down their statements as much as RP writers do.

It is interesting to note that the overall findings of our research parallel in some way those of West (1980) with respect to the frequency of occurrence of that-nominals across the different sections of biology RP. Indeed, West found that that-nominals were very rare in Methods, fairly uncommon in Results, frequent in Discussion and most frequent in Introductions. West explains his findings in functional/communicative terms: he reasons that the fact that the function of the Introduction is to make claims about statements from other research accounts for the high density of that-nominal constructions. Similarly, the Discussion section, which makes many claims about the research findings, contains many that-nominals (and, we can now assert, many hedging tactics). By contrast, the Results and the Methods sections rarely make claims about other statements and are consequently poor in that-nominals (and, as our research showed, in hedging devices).

\section{B. Distribution of hedging categories in Research Papers and Case Reports (with respect to the total number of hedges recorded in each text-type)}

As can be seen in Figure 2, the most frequently used hedging device in RP and CR corresponds to the shield category ( $40.7 \%$ and $34.3 \%$ respectively). In RP these are followed by compound hedges (29.3\%) and approximators (23.2\%), and in CR by approximators (32.5\%) and compound hedges (26.1\%). Nevertheless, although in both text-types shields are the most frequent hedging technique, they are not significantly more frequent than approximators or compound hedges. As our data indicate, these three hedging categories (shields, approximators and compound hedges) account for over $90 \%$ of the total number of hedges used in each text-type. It is interesting to note that the remaining two categories of hedges --which occur with an extremely low frequency in RP and CR 
Figure 2

Percentual Distribution of Hedging Categories in Research

Papers (RP) and Case Reports (CR)

(with respect to the total number of hedges in each text-type)

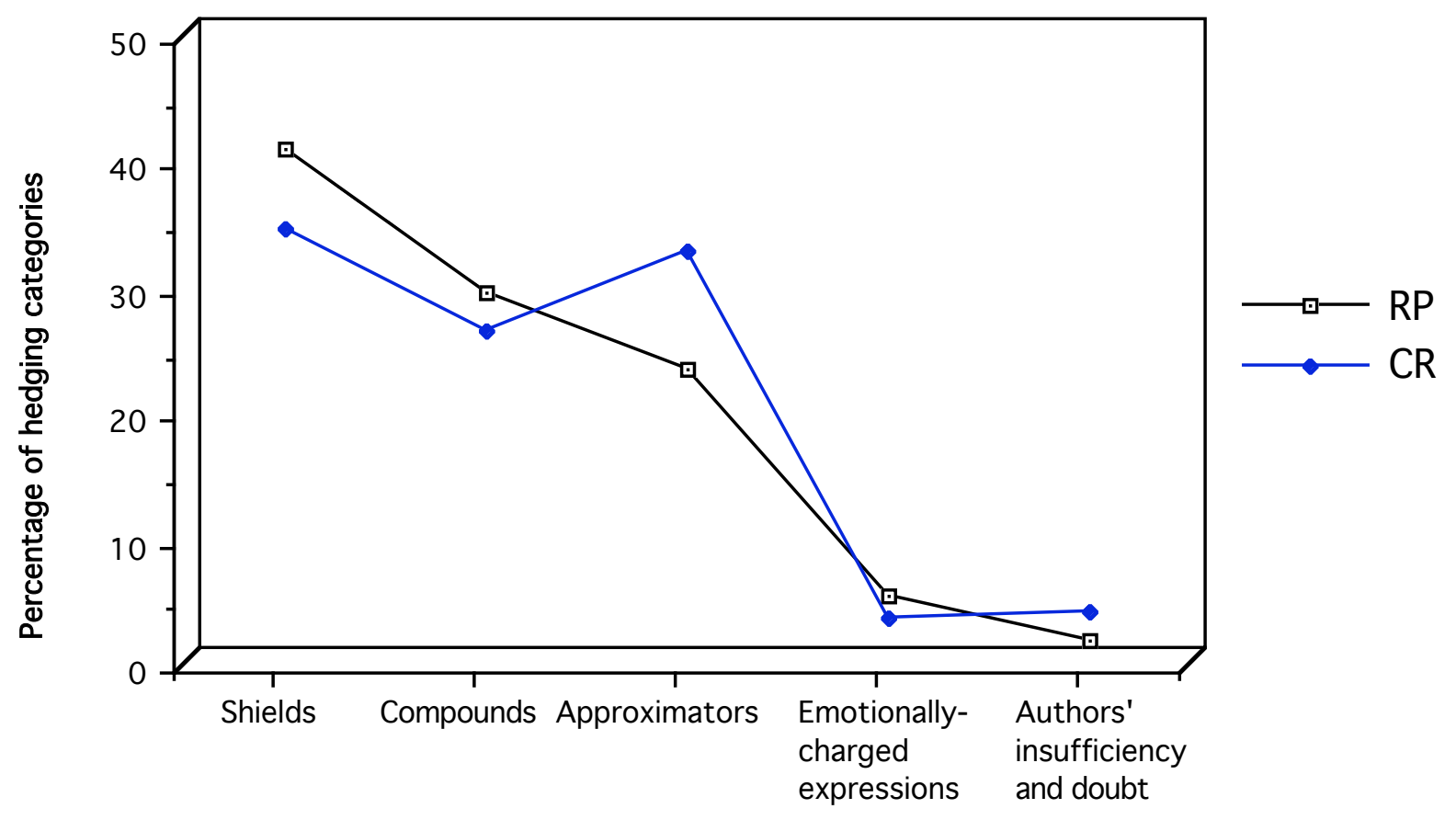

Hedging

Categories 
(they together account for less than 7\% in each text-type)-- were found to be quite frequent in editorials and review articles (cf. Salager-Meyer 1991, 1993).

The frequent use of shields (mostly verbal modality) encountered in RP and CR provides further support to the finding that modals are frequently used in scientific-technical literature to tone down and enhance quantitative and qualitative information as well as to modulate the degree of certainty on the author's part (Selinker 1979, Adams-Smith 1984, Trimble 1985, Vasquez 1987, Kubui 1988, Tarantino 1991b).

Since the distribution of hedges per category differs quite strongly across the IMRAD structure of research papers (as well as across the structural pattern of CR), we will now present our findings in a more detailed fashion by considering the distribution of hedges per category across the different rhetorical sections of RP and CR.

\section{Distribution of Hedging Categories per Rhetorical Section in Research Papers and Case Reports}

C.1. As can be seen on Figures 3 and 4, Introduction sections in both RP and CR favors shields as a hedging convention ( $37.5 \%$ and $44.5 \%$ respectively), followed by approximators in RP (25\%) and by compound hedges in CR $(33.3 \%)$. However, although shields outnumber approximators in the Introduction sections of RP (as well as compound hedges in the Introduction sections of CR), in neither case is the difference statistically significant.

In the Introduction sections of CR and/or RP, shields mostly take the form of epistemic verbs ("to speculate," "to suggest ", "to indicate", "to tend ") and, although less frequently, of modal verbs (see examples below).

- Surveys of physicians and other estimates suggest there exists up to 22.600 alcoholic physicians in the US, or a prevalence of $12 \%$. (RP)

. Earlier studies indicate a cell cycle dependent effect ... (RP)

. Shmerling suggested that sensitization took place during the first hours after birth. (CR)

. Previous estimates of the incidence of acute mountain sickness suggest that ... (RP)

. Alternatively, $\omega-3$ PUFAs may modulate the vasoconstrictor response to pressor hormones and may decrease BP viscosity.(RP)

. Small sample sizes may have hindered the interpretation of many studies.(RP)

- Several lines of evidence suggest that supplementation of diet with fish oils may reduce BP.(CR) 


\section{Figure 3}

\section{Percentual Distribution of Hedging Categories in the Different Rhetorical Sections of Research Papers}

(with respect to the total number of hedges in each section)

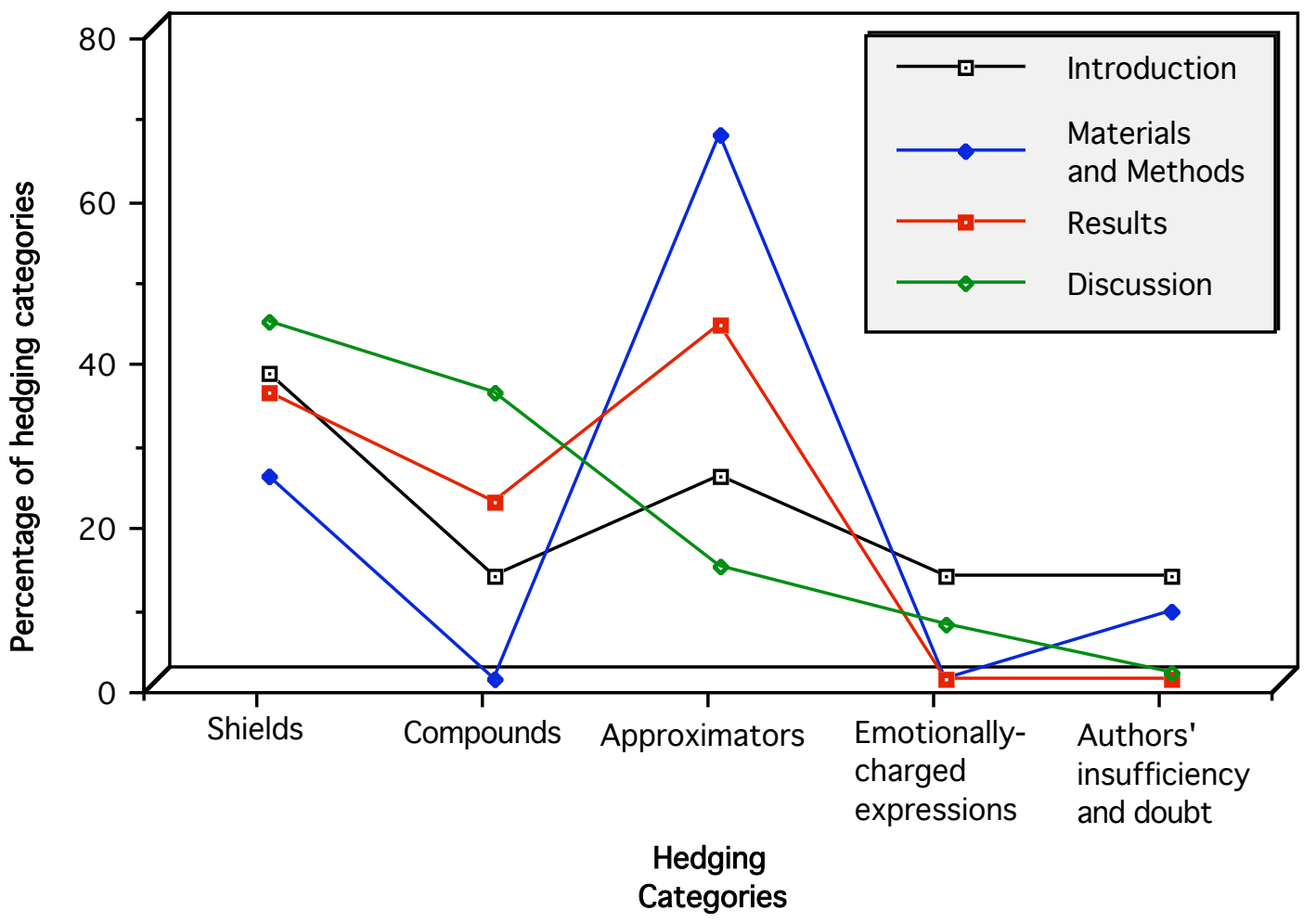




\section{Figure 4}

\section{Percentual Distribution of Hedging Categories in the Different Rhetorical Sections of Case Reports}

(with respect to the total number of hedges in each section)

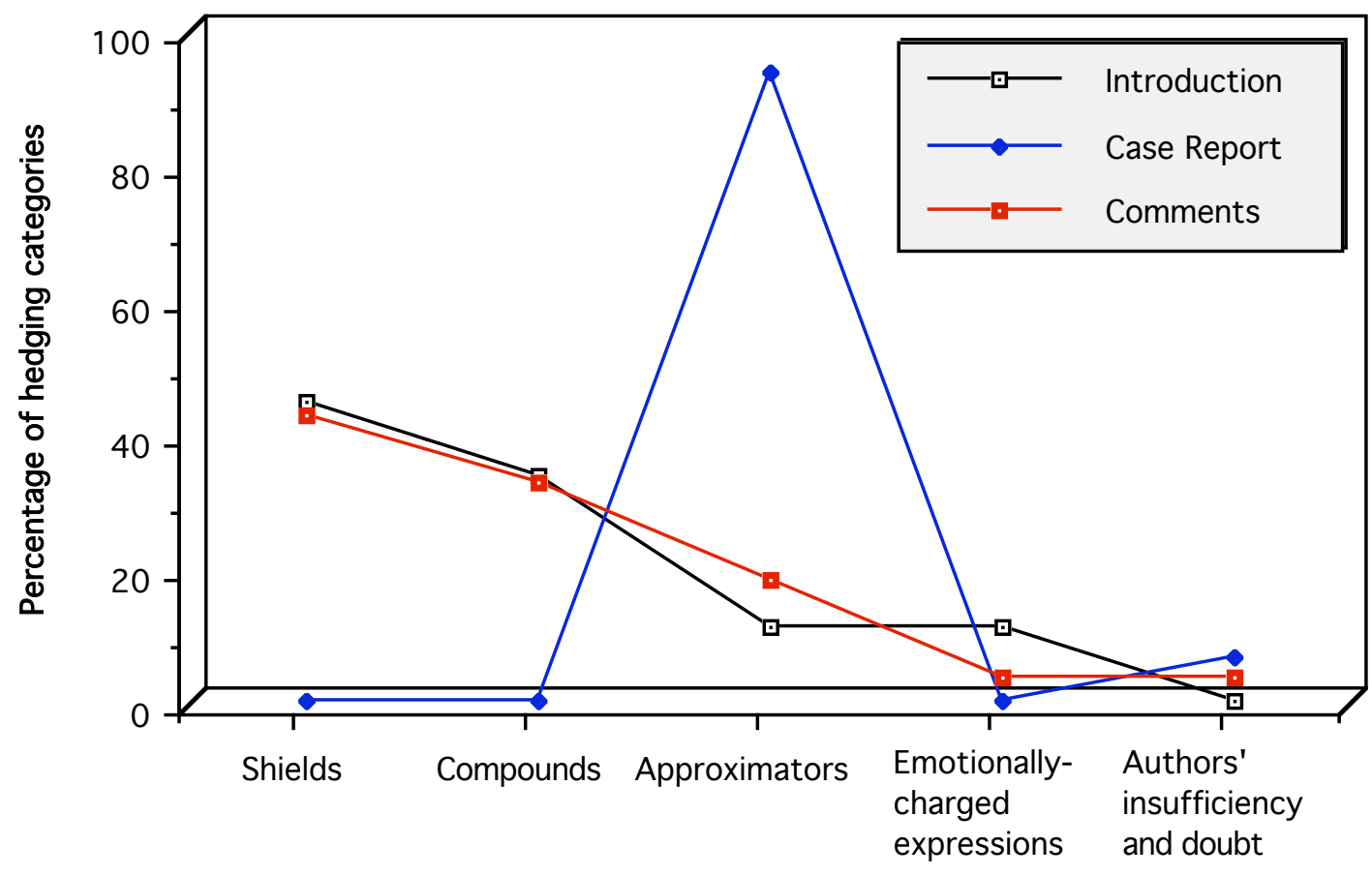

Hedging Categories 
. Several authors have speculated that abnormal aggregation might result in ....In addition, three clinical studies suggested a lower than expected prevalence of ... (RP)

A difference was observed in the use of approximators in the Introductions of CR and that in RP Introductions: indeed, whereas approximators mostly take the form of negative or quasi-negative quantifiers in RP Introductions, they generally correspond to rounders/adaptors of frequency in CR Introductions, as the following examples illustrate:

. There is little research that ... (RP)

. It is therefore quite possible that ...(RP)

. Very few studies have been carried out on ...(RP

. Little information exists on the frequency and severity of the disorder.(RP)

. More needs to be learned about the incidence of ...(RP)

. At present, the mechanism by which $\omega-3$ PUFAs reduce BP remains uncertain..(RP)

. Ciguatera poisoning is usually a clinical diagnosis. (CR)

. Very rarely, primary pneumonia is overwhelming and complicated by respiratory failure. (CR)

From a rhetorical standpoint, Introductions (which Swales called "encapsulated problem-solution texts") motivate the study, justify the reason for the investigation (West 1980: 486) and make claims about statements from other research ${ }^{8}$. The examples presented above (the majority of which illustrate contrastive comments) point to a controversial research area, an important but unresolved issue, and present (especially in RP) evidence which questions existing theory, or calls into question some problems with the accepted knowledge. By citing numerous studies which bear on the same issue, scientists hope to build an argument to support their own work. This, as was said before, serves to justify the publication of the study "by showing that the author's contribution to the discipline, whilst previously established as significant and reference-worthy, is as yet incomplete" (Swales 1990: 138).

To use Gilbert and Mulkay's expression (1984), the examples provided above are part of a "subtle and organized social analysis". The beliefs expressed are presented in a way which enables the authors to contrast them unfavorably with those of another group of scientists, to which the authors themselves belong. What is particularly noticeable about such examples is how the beliefs which they summarize are prepared for immediate rejection. Instead of presenting the central idea as a

8 According to Swales (1990), centrality claims are to be taken as bold statements or appeals to the discourse community whereby members are asked to accept that the research about to be reported is part of a lively, significant or well-established research area. 
reasonable, though inconclusive, interpretation associated with at least some experimental evidence, it is depicted in the text as mere assumption. The impression is conveyed that, although the ideas expressed in such sentences have been around for some time, they have no firm scientific foundation and are not to be taken seriously. The nature of such sentences prepares the readers to expect and welcome the contrasting views to be presented by the researchers in the remaining sentences of their article Introduction. It should be noted that the authors' desire to highlight a knowledge gap (which justifies their own research), and to contrast other researchers' views with their own, is not as intense in CR as it is in RP because, as we previously stated, CR writers do not pretend as much to universality and generalization as RP writers do.

To sum up, all the above examples (typical exponents of modulating signals in the Introduction section of RP and CR) allow the researcher to establish what Swales (1990: 155) calls an "early niche" for the research being reported (as if none of the evidence the researchers are using is conclusive) and to explain what the author's unexplored territory consists of.

C. 2. As stated before, the Methods section of RP is the least hedged division of RP (hedges account for $0.8 \%$ of the total number of running words making up the Methods sections). This relative absence of hedges can be explained by the fact that the Methods section is essentially a listing of procedural formulae, a simple description of the process which led to the obtainment of the data, an elliptical checklist which offers the step-by-step "residual" description of what was done in the laboratory and rarely make claims about other statements (Gilbert and Mulkay 1984, Myers 1985, Huckin 1987). It is then characterized by the virtual absence of problems, matters of discussion (even though the co-authors of the article might have had to discuss the procedures used in the experiment), statement of rationale, discussion of the choices made or evidence of failure. In Swales' terms (1990: 121), the Methods section of a research article is "a highly abstracted reformulation of final outcomes in which an enormous amount is taken for granted". This is why this section can be considered as the most rigid of the four making up the IMRAD pattern, i.e., it can be considered as explicit standard academic description ${ }^{9}$.

Of the 12 hedges recorded in the 5 Methods sections of our sample, 8 (66.7\%) were approximators and $3(25 \%)$ belonged to the shield category. The $\chi^{2}$ test shows that the difference between the frequency of occurrence of both hedging categories is highly significant $(\mathrm{p}=.0001)$. Approximators

\footnotetext{
9 It is interesting to note (cf. Bazerman 1984, Hopkins and Dudley Evans 1988) that the Methods section is increasingly de-emphasized and downgraded to the point where some journals publish it in smaller print than that which is used in the other sections. On the contrary, the Discussion/Conclusion sections have, since 1930, become the most important divisions to the detriment of the Materials/Methods sections. In other words, there has been a marked shift away from the unevaluated reporting to lengthy and explicit writers'comments.
} 
or "rounders" (e.g., "approximately", "usually", "about 5 hours", "roughly the same as") are extremely common in the domain of measurements (henceforth, their justification in the Methods and the Results sections, see C.3. below), but they do not necessarily reflect uncertainty or fuzziness.They are sometimes used as a shorthand device when exact figures are irrelevant or unavailable (Prince et al. 1982).

C.3. Only $3.3 \%$ of the total number of running words making up the 5 Results sections of RPs were hedges (see Fig. 1). The rationale of this low frequency of hedging devices lies in the fact that the Results section of RP is a quite straightforward unfolding of findings: it presents a clear description of the results, describes the process of manipulating the data obtained during the experimental stage, and makes limited claims about the statistical tests. (Such claims are as a rule put forth in the Discussion sections). As for the distribution of hedging categories in the Results sections of RP, it somewhat reflects that observed in the Methods section. Indeed, here too, approximators are the most frequently used hedging device (43.2\%), followed by shields (35.1\%), but, contrary to what was observed in the Methods section of RP, the difference between the frequency of occurrence of these two hedgings categories is not significant.

In the Results section of RP, shields mostly take the form of verbal modality or epistemic verbs, e.g.,

. It can be seen that ...

. These dysfunctions might be slightly overestimated ...

. It appeared that all heat-treated cells progress through mitosis ...

. These results indicate that ... and suggest that the process of DNA synthesis might also show thermotolerance.

It is interesting to remark that the above sentences (especially the last one) correspond rather to an evaluation/ a discussion of the results than to the results per se. Such examples are an indication of a tentativeness on the part of the writers to commit themselves to absolute statements about their results. Whereas observed facts are expressed strongly ("We have found that ") and are not subjected to "maybe", interpretations, explanations and comments on the findings themselves -which express some measure of doubt as to what is actually responsible for the results-- are invariably subjected to such "maybe".

C. 4. The Discussion section "mirror-images the Introduction by moving from specific findings to wider implications" (Swales 1990: 133). According to Huckin (1987), it describes an inside-out circle, whereas the Introduction describes an outside-inside one. This "mirror-imaging" is reflected 
in the use each rhetorical section makes of hedges: as was found in the Introduction sections, the Discussion/Comment sections of RP and CR (see Fig. 3 and 4) is most heavily marked by shields (43.8\% and $42.7 \%$ respectively), followed by compounds (35\% in RP and $32.5 \%$ in CR). Nevertheless, the results of the statistical analysis performed showed that the difference between the frequency of occurrence of these two hedging categories is significant neither in RP nor in CR. It is finally worthwhile mentioning that in the Discussion section (and contrary to what was observed in the Introduction section), shields mostly take the form of verbal modality rather than epistemic verbs.

The primary rhetorical function of this section is to make claims about the research findings (i.e., to explain the statistical findings in non-statistical English), to summarize results, state conclusions and suggestions with reference to previous research and/or to the current work, to set further questions sometimes with possible explanations, references and future developments and applications in the field of study (what Toulmin [1979] refers to as "fertility"). These functions call for analysis and re-synthesis of the information which has to be transmitted through language structures with consequent influence on choice and value of grammatical categories, argument types, functions and exposition strategies (Weaver 1953). Then, the very high frequency of hedges in this section --as compared to that observed in the other three sections--is due to the fact that the claim is the core of the Discussion and, as Tarantino (1991a.) argues, every structure and function in the text must produce reasons for its justification. It is in this last section of research papers that writers speculate, argue, contrast and extrapolate from the described results, and at the same time avoid stating results too conclusively so as the readers can note that the authors are not claiming to have the final word on the subject. Hypotheses are by nature tentative and understated, and this is reflected in their linguistic realization. As McKinlay (1983) observes, for every explanation of the results, there might always be some alternative explanation somebody else might come up with. This explains why it is in this section of RP and CR that compound hedges are most frequently used. The following examples of compound hedges (see below) all illustrate the "clear-cut break between the objective detached reporting found in the Methods/Results sections and the more subjective author involvement in the Discussion/Comments sections." (Adams-Smith 1984).

. It may be possible to give the differential effects a place in the model. (RP)

. Non-invasive methods may suggest the diagnosis (CR).

. Continuous wave Doppler would be expected to delineate ... (CR)

. It seems reasonable to assume that ... (CR)

. The rhythm should be treated accordingly. (CR)

. Several possible factors may be reflected in dental X-rays. (CR) 
. It seems more reasonable to combine measles and measles vaccination together as a possible protective factor against leukemia. (RP)

. Our data may suggest that left ventricular ejection phase indices are fairly normal regardless of the duration of COPD. (CR).

. This can be discussed in terms of .... (RP)

By resorting to such expressions, researchers can avoid absolutes and thus negotiate exactly with what degree of certainty they draw their conclusions and also how strongly they want to align themselves with their claims. Room for disagreement is provided in this way. The above examples illustrate the fact that hedges are a consequence of the fact that research results are indicative rather than definitive.

It has been suggested that the frequent occurrence of such probabilistic concepts (hedging devices) represents an impairment in medical communication and education. Indeed, as Bryant and Norman (1980), Kong et al. (1986), Schwartz and Griffin (1986) and Politser (1987) argue, because the numerical meanings of expressions of likelihood vary greatly from one individual to another, they should be reduced and replaced by numerical ratings, i.e., by an "agreed-upon correspondence" between numbers and other verbal expressions (e.g., it could be agreed that "almost certain " correspond to a $90 \%$ chance, "probable " to a $70 \%$ chance etc.). Such an "agreed-upon code", so argue its proponents, could gradually catch on just as do the meanings of most words encoded in a dictionary. But, as was briefly mentioned in the Introduction of this paper, numbers may communicate unwarranted and/or undesired precision! Claiming precision is not appropriate (sometimes, it is even impossible) in all situations. As Skelton (1988) so rightly remarks, "without hedging, the world would be purely propositional, a rigid and dull place where things either are the case or are not." With a hedging system, Skelton claims, "language is rendered more flexible and the world more subtle."

C.5. The Case Report section of CR presents a very low percentage of hedges, as low as that recorded in the Results sections of RP (3.3\% vs. 3.6\%). This should come as no surprise because the communicative function of both sections is very similar: the Case Report section of CR provides the reader with a listing of the patient's signs and symptoms, the results of the various tests performed on the patient, the diagnosis reached and the outcomes of the treatment administered. It is an essentially factual section, i.e., it avoids commenting on the patients' signs and symptoms, on the results of the tests performed or on those of the treatment administered. Such comments are usually left to the Comment section of CR. 
In the Case Report section of CR, approximators (which make up 93.5\% of the total number of hedges used in that section) mostly take the form of adverbs of quantity, e.g., "almost", "quite", "markedly/greatly enlarged", "slightly irregular". This confirms Prince et al. (1982) finding that such "adaptors" occur most frequently in the description of symptoms in physician-physician (oral) discourse. "Rounders" such as "less than 24 hours later", "on several occasions", "almost 2 hours

", are also very frequent in this section of CR. This is why it is in this section of Case Reports that the frequency of approximators was found to be the highest in our sample $(\mathrm{p}=.0001)$. As was said before (C.3 above), such expressions are mostly used when exact figures are irrelevant or unavailable, or when the authors want to convey the idea of a range, i.e., when they attempt to correlate a particular situation/case with some prototypic or normative situation/case. Almost, approximately, about, quite etc. indicate that the case being described is close (but not similar) to the prototypic situation.

\section{PEDAGOGICAL IMPLICATIONS}

The vagueness used to present information is frequently overlooked by non-native speakers of English (Lackstromn et al. 1972). One reason might be because, as Zuck and Zuck (1987) remarked, little information is available in ESL textbooks to help students familiarize themselves with hedgings. These authors add that the treatment of hedging should at least be sufficient to raise the issue. The same feeling is shared by Rounds (1982), Skelton (1988), Kubui (1988) and Fand (1989) who all agree that hedging in scientific discourse is a necessary and vitally important skill which should be seen as a tool for making thought subtle rather than fudged, and taught to the students in order to assist them in their studies and professional careers. Rounds (1982: 5) considers that hedging is "an important problem [for non-native speakers of English] which is worthy of consideration and instructional attention." Fand (1989) further agrees that consistent categories of "linguistic items linked to bias" might provide helpful guidelines for learners. Non-native speakers of English who want to function in the academic world must be able to recognize hedgings in written texts and use them when necessary in the preparation of their own research work.

Students should be made aware of the need to mediate their claims and of making the difference between observed facts (which, as we said before, are said strongly) and interpretation (i.e., explanations which are invariably subjected to " may be ") in order to be effective readers and writers of scientific genres. The problem lies in the fact that NNSs tend to give the same weight to observed facts and interpretations. Instructors should then teach their students how to choose their reporting verbs; how to make the difference between the verbs whose use asserts the authors' commitment to the attendant proposition (to show, to demonstrate, to establish) and those whose 
use carries no such commitment (to suggest). As Swales (1990: 151) remarks, this distinction "is a powerful rhetorical tool in authors' attempts to create research spaces for themselves because it allows them to signal early whether claims are to be taken as substantiated or not."

I would like to suggest a few exercises which ESP instructors could use in their classes in order to make their students aware of the various techniques (available in English) employed to mitigate and modulate scientific discourse.

a. Sensitization and translation exercises. Students could work in groups and underline all the hedges they can find in an article, justify their use, and provide equivalents (if possible) in their native language. Language instructors could also delete the hedges from a Discussion/Comment section of a scholarly paper and ask their students to rewrite it by hedging it when convenient.

b. Rewriting exercises. It has been demonstrated (Dubois 1986, Fachnestock 1986, Myers 1988) that the tentative note characteristic of research articles is replaced, in popularization articles and in textbooks (Myers 1992) by accredited fact and/or definite assertions ("this suggests the possibility " is replaced by "they discovered ") that need no hedging, and that terms suggesting a possible association are reworded to state a direct cause-effect relationship. Students could then be asked to "rewrite" a popularization article according to the stylistic "hedging guidelines" of present day scientific prose.

\section{Conclusions}

It is clear from the medical data obtained that choice of vague expressions, of tentativeness and flexibility is partly dictated by the general structure of the discourse of this type of academic papers: Introduction (general and vague), the body of the paper itself (particular and precise), and the Conclusion (general and vague), as well as by the general communicative purpose of the written discourse. Our study on hedging in ME prose corroborates the fact that there are discernible differences between sections of research papers (Heslot 1982, Hopkins and Dudley-Evans 1988), and that these sections perform different rhetorical functions which are realized by various linguistic resources (Adams-Smith 1984). The evidence thus suggests a differential distribution of hedging frequency and categories across the standard sections of CR and RP. By and large, we have seen evidence for a two-way division between the extremely low-hedged Methods and Results sections as compared to the heavily hedged Introduction and Discussion/Comment sections of RP and CR. 
Referring to expository writing, Parkhurst (1990) reported that technical vocabulary must be used with complete precision and that adjectives must be avoided as too imprecise. One medical doctor, he reports, describing the need for accuracy, said "We don't say 'pretty small'. We say '2.8 centimeters.' A pretty small tumor does not mean anything. " This seems to contradict reality. It does not seem that science can be as precise as many would like it to be. Hedges are precisely used for that purpose: as Gilbert and Mulkay (1984) assert, scientific rationality is a myth.

We would finally like to suggest at least one line of future research: since the conventions for scientific writing and the style of argumentation has been shown to vary from culture to culture (Galtung 1979, Markkanen and Schröder 1988a.b., Clyne 1991), it would be very interesting to carry out cross-linguistic studies on the way scientific writers modulate their discourse in different text-types and in different languages.

\# This research was supported by grant N. S1-2062 from the Consejo Nacional de Investigaciones Cientificas (CONICIT) and by grant N. M-337-90 from the Consejo de Desarrollo Científico, Humanístico y Tecnológico (CDCHT, Universidad de Los Andes. Mérida. Venezuela).

* We want to express our gratitude to Abdel Fuenmayor (M.D.) for his help and guidance as a specialist informant, to Tony DudleyEvans for his extremely useful comments on an earlier draft of this paper, and to Serge Salager for his technical assistance. 


\section{REFERENCES}

Adams-Smith, D.E. (1983). "Prescribing and general practice: style in medical journals." Paper presented at TESOL Convention.

Adams-Smith, D.E. (1984). "Medical discourse: aspects of author's comments." The ESP Journal. 3: $25-36$.

Bazerman, C. (1984). "Modern evolution of the experimental report in physics. Spectroscopic articles in Physical Review. 1893-1980." Social Studies in Science. 14: 163-96.

Blisset, M. (1972). Politics in Science. Boston: Little, Brown and Co.

Bloor, M. (1984). "Course design: identifying components of a language syllabus. A problem for designers of courses in ESP or communication Studies". ELT Documents. 117. Pergamon Press. The British Council. Oxford. p. 15-24.

Brown, P. and S. Levinson (1978). Politeness: Some Universals in Language Usage. Cambridge: Cambridge University Press.

Bryant, G.D., and G.R. Norman. (1980). "Expressions of probability: words and numbers." New England Journal of Medicine. 302: 411.

Clyne, M. (1991) "The sociocultural dimension: the dilemma of the German-speaking scholar." In Schröder, H. (Ed.). Subject-Oriented Texts. Languages for Special Purposes and Text Theory. de Gruyter. Berlin. 49-68.

Dubois, B.L. (1986) "From New England Journal of Medicine and JAMA through the Associated Press to the local newspaper scientific translation for the laity." In Bungarten T. (Ed.) Wissenschaftssprachen und Gesellschaft: Aspekte der Kommunikation und des Wissenstranfers in der heutigen Zeit. Hamburg: Akademion. 243-53.

Dubois, B.L. (1987). "Something of the order of around 40 to 44 . Imprecise numerical expressions in biomedical slide talks." Language and Society. 16: 525-41.

Fachnestock, J. (1986) "Accomodating science: the rhetorical life of scientific facts." Written Communication. 3: 275-96

Fand, R.J. (1989) "Detecting bias in newspapers: implications for teaching ESL." Reading in a Foreign Language. 6(1): 315-321.

Galtung, J. (1979). "Deductive thinking and political practice. An essay of the teutonic intellectual style style. " In Galtung, J. (Ed.) Papers on Methodology. Essays on Methodology. Vol. II. Copenhagen.

Gilbert, G.N., and M. Mulkay (1984). Opening the Pandora's Box: A Sociological Analysis of $\underline{\text { Scientific Discourse. }}$ Cambridge University Press. 
Heslot, J. (1982). "Tense and other indexical markers in the typology of scientific texts in English." In Hoedt, J. at al. (Eds.) Pragmatics and LSP. Copenhagen : Copenhagen School of Economics: 83-103.

Hopkins, A, and T. Dudley-Evans (1988). "A genre-based investigation of the discussion sections in articles and dissertations." English for Specific Purposes. 7: 113-22.

Huckin, T.N. (1987). Surprise value in scientific discourse. Paper presented at the CCC Convention. Atlanta. Ga. March.

Huddleston, R. (1971). The Sentence in Written English. Cambridge: Cambridge University Press.

Knorr-Cetina, K.D. (1981). The Manufacture of Knowledge. Oxford. Pergamon.

Kong, A., D. Barnett, F. Mosteller and C. Youtz. (1986). "How medical professionals evaluate expressions for probabilities." New England Journal of Medicine. 315. 740-4.

Kubui, A. (1988). Aspects of Hedgings in the Discussion of Medical Research Discourse. LSU ESP Collection. MSc. in TESP Dissertation. University of Aston in Birmingham.

Lakoff, G. (1972). "Hedges: a study in meaning criteria and the logic of fuzzy concepts." Journal of Philosophical Logic. 2: 458-508.

Lachowicz, D. (1981). "On the use of the passive voice for objectivity, author's responsability and hedging in EST." Science of Science. 2(2). 105-115.

Lackstrom, J.E., L. Selinker, and L. Trimble (1972). "Grammar and technical English." English Teaching Forum. 10(5): 3-14.

Lock, S. (1988). "Structured abstracts." British Medical Journal. 297: 156.

Markkanen, R., and H. Schröder (1988a.). "Hedging and its linguistic realizations in German, English and Finnish philosophical texts: a case study." Erikoiskielet ja Käänösteoria. VAAKI Seminarii. VII. Vaasa. Finland.

Markkanen, R., and H. Schröder (1988b.). "Hedging as a translation problem in scientific texts." In C. Laurén and M. Nordman (Eds.) Special Language: From Human Thinking to Thinking Machines. Multilingual Matters. Clevedon. 171-180.

McKinlay, J. (1983). " An analysis of the discussion sections of medical journal articles." MSc Dissertation. University of Birmingham.

Myers, G. (1985). "Texts as knowledge claims: the social constructions of two biology articles." Social Studies of Science. 15: 593-630.

Myers, G. (1988) "The pragmatics of politeness in scientific articles." Applied Linguistics. 10: 135.

Myers, G.A. (1992). "Textbooks and the sociology of science." English for Specific Purposes. 11(1), 3-19.

Pindi, M. and T. Bloor (1986) "Playing safe with predictions: hedging, attribution and conditions in economic forecasting." Written Language. BAAL. 2. CILT. 
Politser, P.E. (1987). "Medical education for a changing future: new concepts for revising texts." Medical Education. 21: 320-33.

Powell, M.J. (1985). " Purposive vagueness: an evaluation dimension of vague quantifying expressions." Journal of Linguistics. 21: 31-50.

Prince, E.F., R.J. Frader and C. Bosk (1982). "On hedging in physician-physician discourse." In J. di Prieto (Ed.) Linguistics and the Professions. Ablex Publishing Corporation. : 83-97.

Rounds, P. (1981). "On hedging in social science written texts." University of Michigan (Mimeo)

Rounds, P. (1982). "Hedging in written academic discourse: precision and flexibility." (Mimeo). University of Michigan.

Salager-Meyer, F. (1991). "Hedging in Medical discourse: 1980-1990." Interface. 6(1). 33-54.

Salager-Meyer, F. (1993). "Imprecision and vagueness (hedging) in today's medical discourse: courtesy, coyness or necessity?" The ESPecialist. 14(1), 1-15.

Schwartz, S., and T. Griffin (1986). Medical Thinking. Springer-Verlag. Berlin.

Selinker, L. (1979). "On the use of informants in discourse analysis and language for specialized purposes." IRAL. 27(3).

Skelton, J. (1988). "Care and maintenance of hedges." ELT Journal. 42(1): 37-43.

Stubb, M. (1986). " A matter of prolonged field work : notes toward a modal grammar of English" Applied Linguistics. 7(1): 1-25.

Swales, J. (1981) Aspects of Article Introductions. Aston University ESP Research Reports No 1. The University of Aston in Birmingham.

Swales, J. (1987). "Utilizing the literature in teaching the research paper." TESOL Quarterly. 22 (1). 41-67.

Swales, J. 1990. Genre Analysis. Cambridge University Press.

Tarantino, M. (1991a.). "Scientific English: qualitative factors via modern rhetoric." UNESCOALSED LSP Newsletter. 13(3): 51-60.

Tarantino, M. (1991b). "EST: Dispassionate discourse and the discreet presence." UNESCOALSED-LSP Newsletter. 13(4), p.28-34.

Toulmin, S. (1958). The Uses of Arguments. Cambridge. CUP.

Toulmin, S. (1979). An Introduction to Reasoning. New York: Macmillan.

Trimble, L. (1985) English for Science and Technology: A Discourse Approach. Cambridge University Press.

Vasquez, F. (1987) A comparative Study of the Rhetorical Structure of the Discussion Sections in English and Spanish Medical Articles. Msc. TESP. Aston University.

Weaver, R.M. (1953). The Ethics of Rhetoric. Chicago. Henri Regnery.

West, G.K. (1980). "That-nominals constructions in traditional rhetorical divisions of scientific research papers." TESOL Quarterly. 14: 483-9. 
Yearley, S. (1981). "Textual persuasion: the role of social accounting in the constructions of scientific arguments." Journal of Sociology of Science. $11: 409-35$.

Zuck, J.G., and L.V. Zuck (1987). "Hedging in newswriting." In A.M. Cornu, J. Vanparijs, and M. Delahaye (Eds.) Beads or Bracelets: How Do We Approach LSP? Leuven: Oxford University Press. p. 172-181. 
Francoise Salager-Meyer holds a B.A. and an M.A. in Russian Literature and Linguistics from the University of Lyons (France) and a Ph.D. in Foreign Language Education from the University of Texas at Austin. She is currently teaching English for Specific Purposes and Russian at the Universidad de Los Andes (Mérida, Venezuela). She is the author of Medical English: A Scientific $\underline{\text { Reading course, }}$ and of several articles --mostly concerned with medical discourse-- which appeared in Text, Reading in a Foreign Language, Interface, English for Specific Purposes. 